\title{
Potential of Solar Heating for Ultra-Low-Energy Passive Buildings in Cold Regions
}

\author{
Jiwei $\mathrm{Li}^{1}$, Yingchun $\mathrm{Cao}^{1,2^{*}}$, Qi Wang ${ }^{1}$, Bingling $\mathrm{Niu}^{1}$ \\ ${ }^{1}$ College of Civil Engineering and Architecture, Hebei University, Baoding 071002, China \\ ${ }^{2}$ School of Architecture and Art, Hebei University of Architecture, Zhangjiakou 075000, China
}

Corresponding Author Email: 1014206030@tju.edu.cn

https://doi.org/10.18280/ijht.370414

Received: 15 April 2019

Accepted: 3 August 2019

\section{Keywords:}

ultra-low-energy (ULE) passive

buildings, solar heating, heating factors, potential

\begin{abstract}
The ultra-low-energy (ULE) passive buildings are an important trend of building energy conservation. China has been steadily pushing forward energy-saving policies for buildings, and started to promote the ULE passive buildings. Solar heating has a great application potential in the ULE passive buildings, which are required to consume a very low amount of energy. This paper establishes a simplified model of slab-type residential unit in cold regions of northern China, and correlates the areas of solar heating available on the south wall and the roof with the heating loss of the building, according to the change law of solar radiation. In addition, the calculation formulas for wall and roof heating factors were proposed under the ULE condition, and applied to compute the heating factors of major cities in northern China. The calculation results verify the effectiveness of the formulas. Through statistical analysis, it is learned that wall and roof heating factors are closely correlated with the regional latitude. Hence, the relationship between them were fitted, and verified by a case study in Shijiazhuang, China. The fitted relationship was proved correct, laying the basis for fast and accurate evaluation of solar heating potential in cold regions.
\end{abstract}

\section{INTRODUCTION}

In recent years, the environmental awareness is growing among ordinary people. The energy consumption of buildings has become a major influencing factor of the environment [1]. During their operations, buildings consume a huge amount of energy, emitting lots of greenhouse gases (GHGs) into the air [2]. It is a common desire to control building energy consumption [3], and reduce its environmental impact [4]. In developed countries of Europe and North America, many newly constructed buildings consume zero energy [5], and even produce energy [6]. By contrast, the development energy-saving buildings is still in its infancy in China.

In cold regions, heating takes up a major part of building energy consumption [7]. The reduction of heating energy consumption has long been a research hotspot [8]. The relevant studies mostly focus on two aspects. The first aspect is to reduce heating energy consumption through energysaving design. For example, China has implemented progressive energy-saving policies. The energy-saving goal was $30 \%$ in the $1980 \mathrm{~s}, 50 \%$ in the 1990 s and $65 \%$ in the early $21^{\text {st }}$ century [9]. Many cities and regions in China have introduced foreign energy-saving techniques and rolled out policies to develop ultra-low-energy (ULE) passive buildings [10]. The other aspect is to strengthen the use of renewable energy [11] and reduce the proportion of conventional energy sources in the energy structure, e.g. resorting to solar heating [12].

With the advancement of science and technology, great progress has been made in the energy-saving techniques for buildings, including efficient use of solar energy [13], energysaving envelope structure [14], energy-saving doors and windows [15] and application of phase change heat storage materials [16]. In northern China, the incentive policies on the ULE passive buildings provide a strong support to the use of solar heating in buildings [17]. Scholars at home and abroad have explored extensively into solar heating [18]. However, these studies are too professional to be mastered by general designers [19]. Little attention has been paid to making general designers determine the solar heating parameters, both rapidly and effectively, as per energy-saving requirements.

Focusing on buildings in cold regions in northern China, this paper correlates the solar energy available on wall and roof in the heating season with the heating energy consumption in the ULE mode, and obtains a fast and accurate method to calculate the potential of solar energy utilization for heating. The research results facilitate the solar heating design for general designers.

\section{METHODOLOGY}

\subsection{Simplifed model of solar heating buildings}

Before implementing solar heating for a building, it is necessary to determine how much solar energy the building can acquire, and the heating energy consumption of the building throughout the heating season. In winter, the sunshine duration is relatively short. The building mainly acquires the solar energy via the south wall and the roof [20]. Thus, these two surfaces of the building were taken as the research objects. First, a simplified model of slab-type residential unit was established (Figure 1). The maximum size of the wall-mounted solar collector $S_{\text {wall,c }}$ can be expressed as:

$$
S_{\text {wall }, c}=a \times h-a_{\text {win }} \times h_{\text {win }}
$$


The maximum size of the roof-mounted solar collector $S_{\text {roof, }}$ can be expressed as:

$$
S_{\text {roof,c }}=a \times L
$$

The building area of the established model $S_{\text {buil }}$ can be calculated by:

$$
S_{b u l l}=a \times L
$$

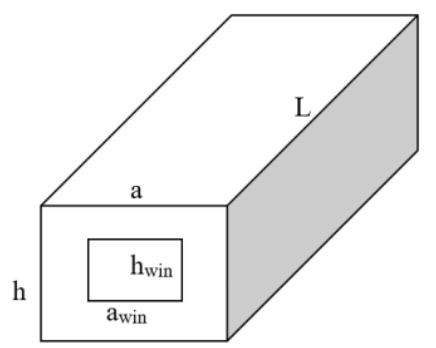

Figure 1. Simplified model of slab-type residential unit

\subsection{Solar energy on south wall and roof and unit heat consumption index}

The following works should be done before judging if the radiation received on building surfaces can satisfy the heating demand of the building: identifying the law of sunshine and building energy consumption, examining the solar energy received on building surfaces, and determining the heating energy consumption of the building.

\subsubsection{Solar radiation acquired on building surfaces}

The intensity of direct solar radiation on the ground can be computed by [21]:

$$
I_{D N}=I_{0} P^{m}
$$

The intensity of direct solar radiation on an inclined surface with random orientation and inclination (Figure 2) can be computed by [22]:

$$
I_{D}=I_{D N}[\cos \theta \sinh +\sin \theta \cos h \cos (\alpha-\gamma)]
$$

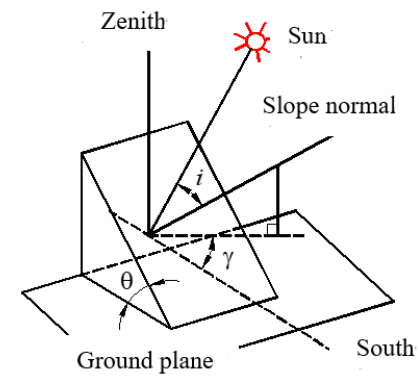

Figure 2. Solar rays on an inclined surface on the ground

The total intensity of solar radiation on an inclined surface with random orientation and inclination can be obtained by [23]:

$$
I_{\theta}=I_{D \theta}+\left(\frac{1+\cos \theta}{2}\right) I_{H S}+I_{r}
$$

The inclination of the wall is $90^{\circ}$. Then, the intensity of solar radiation received by a vertical wall $I_{\text {wall }}$ can be obtained by:

$$
I_{\text {wall }}=I_{D N}[\cosh \cos (\alpha-\gamma)]+\frac{1}{2} I_{H S}+I_{r}
$$

The daily solar radiation energy received by the wall $H_{\text {wall }}$ can be described as:

$$
H_{\text {wall }}=I_{\text {wall }} \mathrm{S}_{\text {wall }} \int_{T_{\text {sta }}}^{T_{\text {end }}} d T
$$

The inclination of the roof is $0^{\circ}$. Then, the intensity of solar radiation received by the horizontal roof $I_{\text {roof }}$ can be obtained by:

$$
\mathrm{I}_{\text {roof }}=I_{D N} \sin (h)+\frac{1}{2} I_{H S}
$$

The daily solar radiation energy received by the roof $H_{\text {wall }}$ can be described:

$$
H_{\text {wall }}=I_{\text {wall }} S_{\text {wall }} \int_{T_{\text {sta }}}^{T_{\text {end }}} d T
$$

\subsubsection{Heating energy consumption of the building}

In a cold region, the heating energy consumption of a building is usually described by the heating loss index $q_{H}$. The heating loss of the building refers to the heat supplied to the indoor heating equipment per building area in a unit time to maintain the calculated indoor temperature, under the mean temperature of the heating season:

$$
q_{H}=q_{H T}+q_{I N F}-q_{I H}
$$

\section{RESULTS}

Under ideal conditions, the heating demand of a building should be satisfied by the solar energy acquired by the building. Suppose the building has a sufficiently large energy storage device. Then, the building should acquire enough solar energy, such that the thermal energy converted from the solar energy can offset the heating energy consumption of the building. As mentioned before, the building mainly acquires the solar energy via the south wall and the roof in winter. Hence, these two building surfaces are the focus of the subsequent analysis:

\subsection{Relationship between solar heating potential of south wall and heating loss of the building}

During the heating season, the solar heating energy acquired by the building via the south wall $H_{q \text {,win }}$ can be defined as:

$$
H_{q, \text { win }}=\eta \sum_{Z_{0}}^{Z} H_{q, \text { wall }}
$$

During the heating seasons, the heating energy consumption of the building, i.e. its heating loss $Q_{\text {heat }}$ [24], can be described as:

$$
Q_{\text {heat }}=24 z q_{h} S_{\text {buil }}
$$


If the solar heating energy can fully satisfy the heating loss, we have:

$$
Q_{\text {heat }}=H_{q, \text { win }}
$$

Sorting out formulas (1)-(14), we have:

$$
q_{h}=\frac{\eta S_{\text {wall }} \sum_{Z_{z y}}^{Z} \int_{T_{\text {sud }}}^{T_{\text {oud }}} I_{0} p^{m}\left\{[\cosh \cos (\alpha-\gamma)] I_{D N}[\cosh \cos (\alpha-\gamma)]+\frac{1}{2} I_{H S}+I_{r}\right\} d T}{24 z S_{\text {buil }}}
$$

For a specific region, the above formula can be rewritten as:

$$
\frac{S_{\text {wall }} \sum_{Z_{\text {in }}}^{Z} \int_{T_{\text {sad }}}^{T_{\text {end }}} I_{0} p^{m}\left\{[\cosh \cos (\alpha-\gamma)] I_{D N}[\cosh \cos (\alpha-\gamma)]+\frac{1}{2} I_{H S}+I_{r}\right\} d T}{24 z}
$$

Formula (16) can be considered as a constant. Here, it is defined as the regional radiation constant $N_{q}$ for the vertical wall. Then, formula (15) can be expressed as:

$$
q_{h}=\frac{\eta S_{\text {wall }}}{S_{\text {buil }}} N_{\mathrm{q}}
$$

In this case, the heating loss index is only correlated with the heat collection area of the wall, the building area, and the efficiency of the solar collector. Specifically, the heating loss has a positive correlation with the heat collection area of the wall and a negative correlation with the building area.

Hence, formula (15) can be converted into:

$$
\frac{N_{q}}{q_{h}}=\frac{S_{\text {buil }}}{\eta S_{\text {wall }}}
$$

The heating loss index $\mathrm{q}_{\mathrm{H}}$ of buildings is a fixed value in a specific region. Hence, the value of $N_{q} / q_{H}$ must be a constant. Here, the $N_{q} / q_{H}$ value is defined as the solar heating factor of vertical wall (wall heating factor) $M_{w}$ :

$$
M_{w}=\frac{S_{\text {buil }}}{\eta S_{\text {wall }}}
$$

\subsection{Relationship between solar heating potential of roof and heating loss of the building}

Similarly, the solar heating energy acquired by the building via the roof $H_{\mathrm{w} \text {,win }}$ through the heating season can be defined as:

$$
H_{w, w i n}=\eta \sum_{Z_{0}}^{Z} H_{r o o f}
$$

If the solar heating energy can fully satisfy the heating loss, $H_{w \text {, win }}$ must be equal to $Q_{\text {heat }}$.

Sorting out formulas (1)-(20), a floor parameter $(n)$ was introduced, for the roof can supply energy to different floors in the building:

$q_{h}=\frac{\eta S_{\text {roof }} \sum_{\mathrm{z}_{0}}^{Z} \int_{T_{\text {sad }}}^{T_{\text {out }}} I_{0} p^{m}\left\{[\cosh \cos (\alpha-\gamma)] I_{D N}[\cosh \cos (\alpha-\gamma)]+\frac{1}{2} I_{H S}+I_{r}\right\} d T}{24 z n S_{\text {buil }}}$

For a specific region, we have:
$\frac{S_{\text {roof }} \sum_{Z_{0}}^{Z} \int_{T_{\text {sud }}}^{T_{\text {end }}} I_{0} p^{m}\left\{[\cosh \cos (\alpha-\gamma)] I_{D N}[\cosh \cos (\alpha-\gamma)]+\frac{1}{2} I_{H S}+I_{r}\right\} d T}{24 z}$

Formula (22) can be considered as a constant. Here, it is defined as the regional radiation constant $N_{r}$ for the horizontal roof. Then, formula (21) can be expressed as:

$$
q_{h}=\frac{\eta S_{\text {roof }}}{n S_{\text {buil }}} N_{r}
$$

Similar to the calculation principle of the wall, formula (23) can be converted into:

$$
\frac{N_{r}}{q_{H}}=\frac{n S_{\text {buil }}}{\eta S_{\text {roof }}}
$$

The heating loss index $q_{H}$ of buildings is a fixed value in a specific region. Hence, the value of $N r / q_{H}$ must be a constant. Here, the $N r / q_{H}$ value is defined as the solar heating factor of horizontal roof (roof heating factor) $M_{r}$ :

$$
M_{r}=\frac{n S_{\text {buil }}}{\eta S_{\text {roof }}}
$$

\subsection{Validation of the calculation method for solar heating potential}

Our calculation method for solar heating potential was verified based on the parameters of Tian Binshou, Shao et al. [25] in their research on winter solar heating for a single-story building in Kangxian County, Gansu Province, China. The specific parameters are as follows:

Geographical location: $33^{\circ} 20^{\prime} \mathrm{N}, 105^{\circ} 36^{\prime}$; building area: $155.76 \mathrm{~m}^{2}$; heating time: $8 \mathrm{~h} / \mathrm{d}$; building heating loss $33 \mathrm{~W} / \mathrm{m}^{2}$; heating load $45 \mathrm{~W} / \mathrm{m}^{2}$; overall efficiency of solar heating: 0.40 ; solar collector area: $21.6 \mathrm{~m}^{2}$; collector inclination: $50^{\circ}$; collector location: roof; compensation ratio of north-south orientation: 0.94 .

Based on the above parameters, the solar collector area was designed based on our calculation principle. The inclination of the roof-mounted solar collector $50^{\circ}$ was substituted into formulas (1)-(20) for calculation. The results show that the roof heating factor with the inclination of $50^{\circ}$ was 5.60. If the solar radiation received by the collector needs to supply $67.5 \%$ of energy to the building for $8 \mathrm{~h}$ each day, then the solar collector should be $16.64 \mathrm{~m}^{2}$ in size. Considering the overall heating load, the area of the solar collector was modified as $22.70 \mathrm{~m}^{2}$, only $1.1 \mathrm{~m}^{2}$ smaller than the actual design of $21.6 \mathrm{~m}^{2}$. The small error $(4.9 \%)$ indicates that our calculation method can complete preliminary evaluation of solar heating design in an accurate and rapid manner.

\subsection{Wall and roof heating factors under the ULE condition}

The solar collector is normally mounted on the wall or on the roof. Under the known solar heating efficiency, it is only necessary to compute the wall or roof heating factor to judge if the area of south wall or roof in a region could satisfy the heating demand. The radiation constants and heating factors in main cities of northern China were calculated based on the heating data of the ULE buildings and the Standard for Energy-Saving Design of Ultra-Low-Energy Passive 
Table 1. Radiation constants and heating factors in main cities of northern China

\begin{tabular}{|c|c|c|c|c|c|c|c|c|c|}
\hline $\begin{array}{c}\text { Serial } \\
\text { no. }\end{array}$ & City & Latitude & $\begin{array}{c}\text { Heating } \\
\text { period }\end{array}$ & $\begin{array}{l}\text { Number of } \\
\text { heating } \\
\text { days (day) }\end{array}$ & $\begin{array}{c}\text { Heat loss } \\
\text { per unit } \\
\text { time }(\mathrm{h} \\
\left.\mathrm{W} / \mathbf{m}^{2}\right) \\
\end{array}$ & $\begin{array}{c}\text { Wall } \\
\text { radiation } \\
\text { factor }(\mathbf{h} \\
\left.\mathbf{W} / \mathbf{m}^{2}\right) \\
\end{array}$ & $\begin{array}{c}\text { Wall } \\
\text { heating } \\
\text { factor }\end{array}$ & $\begin{array}{c}\text { Roof } \\
\text { radiation } \\
\text { factor }(\mathbf{h} \\
\left.\mathrm{W} / \mathbf{m}^{2}\right) \\
\end{array}$ & $\begin{array}{c}\text { Roof } \\
\text { heating } \\
\text { factor }\end{array}$ \\
\hline 1 & Xi'an & $34^{\circ} 15^{\prime}$ & $\begin{array}{c}11.15- \\
3.15\end{array}$ & 121 & 9.80 & 158.72 & 16.20 & 126.23 & 12.88 \\
\hline 2 & Zhengzhou & $34^{\circ} 44^{\prime}$ & $\begin{array}{c}11.15- \\
3.15\end{array}$ & 121 & 9.80 & 157.77 & 16.10 & 123.8 & 12.63 \\
\hline 3 & Qingdao & $36^{\circ} 04^{\prime}$ & $11.15-4.5$ & 145 & 9.90 & 154.91 & 15.65 & 133.89 & 13.53 \\
\hline 4 & Jinan & $36^{\circ} 40^{\prime}$ & $\begin{array}{c}11.15- \\
3.15\end{array}$ & 120 & 9.90 & 153.42 & 15.50 & 114.05 & 11.52 \\
\hline 5 & Taiyuan & $37^{\circ} 51^{\prime}$ & $11.1-3.30$ & 150 & 10.19 & 152.80 & 14.99 & 121.57 & 11.93 \\
\hline 6 & Shijiazhuang & $38^{\circ} 03^{\prime}$ & $\begin{array}{c}11.15- \\
3.15\end{array}$ & 121 & 9.95 & 149.86 & 15.06 & 107.17 & 10.77 \\
\hline 7 & Dalian & $38^{\circ} 54^{\prime}$ & $11.5-3.30$ & 145 & 10.09 & 149.91 & 14.86 & 114.7 & 11.37 \\
\hline 8 & Tianjin & $39^{\circ} 17^{\prime}$ & $\begin{array}{c}11.15- \\
3.15\end{array}$ & 121 & 10.05 & 146.70 & 14.60 & 101.64 & 10.12 \\
\hline 9 & Beijing & $39^{\circ} 54^{\prime}$ & $\begin{array}{c}11.15- \\
3.15\end{array}$ & 121 & 9.95 & 144.69 & 14.54 & 98.05 & 9.85 \\
\hline 10 & Hohhot & $40^{\circ} 48^{\prime}$ & $\begin{array}{c}10.15- \\
4.15\end{array}$ & 185 & 10.44 & 146.81 & 14.06 & 118.3 & 11.33 \\
\hline 11 & Shenyang & $41^{\circ} 48^{\prime}$ & $11.1-3.30$ & 150 & 10.39 & 141.63 & 13.63 & 100.6 & 9.68 \\
\hline 12 & Urumqi & $43^{\circ} 46^{\prime}$ & $\begin{array}{c}10.15- \\
4.15\end{array}$ & 185 & 10.68 & 138.99 & 13.01 & 104.2 & 9.75 \\
\hline 13 & Changchun & $43^{\circ} 55^{\prime}$ & $\begin{array}{c}10.25- \\
4.10 \\
\end{array}$ & 170 & 10.63 & 137.04 & 12.89 & 98.68 & 9.28 \\
\hline 14 & Harbin & $45^{\circ} 45^{\prime}$ & $\begin{array}{c}10.20- \\
4.20 \\
\end{array}$ & 185 & 10.73 & 132.85 & 12.38 & 98.67 & 9.19 \\
\hline
\end{tabular}

\subsection{Correlation between heating factors and latitude}

The following laws can be discovered from the data in Table 1:

(1) The heating factors have certain correlations with latitude: the higher the latitude, the smaller the heating factors, and the more unfavorable for solar heating (Figure 3).

(2) The correlation coefficient between latitude and wall heating factor was -0.997 , indicating a high correlation between the two factors; the correlation coefficient between latitude and roof heating factor was -0.88 , also a sign of high correlation.

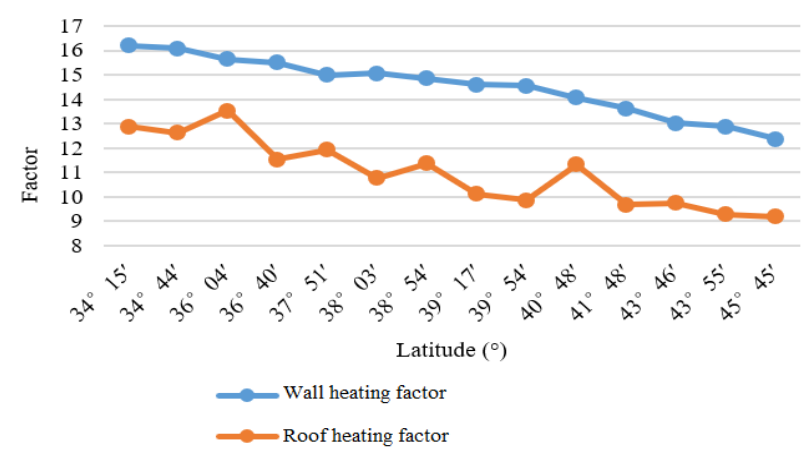

Figure 3. Relationship between latitude and heating factors

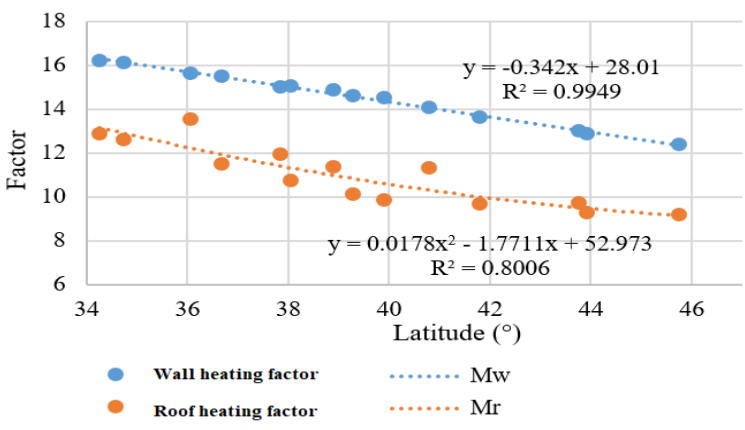

Figure 4. Fitted relationship curves between latitude and heating factors 
Figure 4 can be obtained through data fitting. The correlation between latitude and wall heating factor can be obtained from the fitted relationship curves. The correlation coefficient (0.9949) can be determined by:

$$
M_{w}=-0.342 \phi+28.01
$$

The correlation between latitude and wall heating factor can also be obtained from the fitted relationship curves. The correlation coefficient $(0.8006)$ can be determined by:

$$
M_{\mathrm{r}}=0.0178 \phi^{2}-1.7711 \phi+52.973
$$

The wall and roof heating factors in cold regions of northern China can be derived through the above two formulas.

\section{DISCUSSION}

\subsection{Verification of heating factors}

First, Shijiazhuang (latitude: $38^{\circ} 03^{\prime} \mathrm{N}$ ) was adopted to verify the heating factors. The wall heating factor was calculated by formula (26) as $15.00,4 \%$ smaller than the actual value (15.06) obtained by formulas (1)-(19); the roof heating factor was calculated by formula (27) as $11.35,5.14 \%$ greater than the actual value (10.77) obtained by formulas (1)-(20). The results are acceptable for preliminary evaluation of solar heating design; Next, Tianjin (latitude: $39^{\circ} 17^{\prime}$ ) was adopted to verify the heating factors. The wall heating factor was calculated by formula (26) as $15.00,2.8 \%$ greater than the actual value (14.58) obtained by formulas (1)-(19); the roof heating factor was calculated by formula (27) as $10.12,6.89 \%$ smaller than the actual value (10.87) obtained by formulas (1)(20). The results are acceptable for preliminary evaluation of solar heating design. The above results show that formulas (26) and (27) can be used for quick calculation of regional heating factors in the design phase of solar heating plans for buildings.

\subsection{Evaluation of solar heating potential based on heating factors}

According to relevant regulations on energy-saving of residential buildings, the window-wall ratio on the south wall of residential buildings should not surpass 0.35 [26]. Thus, about $65 \%$ of the south wall can be used to receive solar energy. On this basis, the area of the wall of a building that can receive solar energy can be described as:

$$
\begin{aligned}
S_{\text {wall }}= & 0.65 \times a \times h \\
& S_{\text {buil }}=a \times h \times \mathrm{L}
\end{aligned}
$$

In this case, formula (19) can be converted into:

$$
M_{w}=L /(0.65 \eta h)
$$

According to Table 1, the wall heating factor is 15.00 in Shijiazhuang. Suppose the solar heating efficiency $\eta$ is 0.35 . Then, the value of $L / h$ was 3.31 . If the floor height is $2.8 \mathrm{~m}$, the building solely relying on the south wall for heating should not be deeper than $9.23 \mathrm{~m}$. However, the normal depth of residential buildings is about $12 \mathrm{~m}$. Obviously, it is impossible for ULE buildings in Shijiazhuang to realize solar heating based on the south wall only. The south wall could supply about $75 \%$ of the heating energy. The remaining $25 \%$ can be supplied by the roof solar collector. The area of the roof of a building that can receive solar energy can be described as:

$$
\begin{gathered}
S_{\text {roof }}=a \times L \\
S_{\text {buil }}=n \times a \times \mathrm{L}
\end{gathered}
$$

where, $n$ is the number of floors in the building.

In this case, formula (19) can be converted into:

$$
M_{w}=n / \eta a \times h \times \mathrm{L}
$$

The $n$ value can be calculated as 3.54 , i.e. the solar energy collected on the roof can support the heating of 3.54 floors. Since the roof only needs to provide $25 \%$ of the heating energy to each floor, the solar energy collected by the roof and south wall combined can satisfy the heating demand of a 14-story building. Therefore, the ULE passive buildings in Shijiazhuang can adopt solar heating in winter.

\section{CONCLUSIONS}

The concept of solar heating factor was proposed, allowing the designers to evaluate the solar heating effect early in the design. The wall and roof heating factors were correlated with latitudes of major cities in northern China. In this way, the relationship between heating factors and latitude was summarized for the ULE passive buildings, and verified through a case study on a solar heating residential building in Kangxian County, Gansu Province, China. The author also put forward the calculation method for the relationship between the solar collector area needed for solar heating and building area, facilitating the design and calculation of solar heating in the design phase.

\section{ACKNOWLEDGMENT}

This research was funded by Hebei Education Department (QN2019187), National Natural Science Foundation of China (51708394), National Training Program of Innovation and Entrepreneurship for Undergraduates (201910075003).

\section{REFERENCES}

[1] Mauree, D., Coccolo, S., Kaempf, J., Scartezzini, J.L. (2017). Multi-scale modelling to evaluate building energy consumption at the neighbourhood scale. PloS One, 12(9): e0183437. https://doi.org/10.1371/journal.pone.0183437

[2] Abanda, F.H., Tah, J.H.M., Cheung, F.K.T. (2013). Mathematical modelling of embodied energy, greenhouse gases, waste, time-cost parameters of building projects: A review. Building and Environment, 59: 23-37. https://doi.org/10.1016/j.buildenv.2012.07.014

[3] Reynolds, J., Rezgui, Y., Kwan, A., Piriou, S. (2018). A zone-level, building energy optimisation combining an artificial neural network, a genetic algorithm, and model predictive control. Energy, 151: 729-739. 
https://doi.org/10.1016/j.energy.2018.03.113

[4] Mao, X.K., Wang, L.X., Li, J.W., Quan, X.L., Wu, T.Y. (2019). Comparison of regression models for estimation of carbon emissions during building's lifecycle using designing factors: A case study of residential buildings in Tianjin, China. Energy and Buildings, 204: 109519. https://doi.org/10.1016/j.enbuild.2019.109519

[5] Castaldo, V.L., Pisello, A.L., Piselli, C., Fabiani, C., Cotana, F., Santamouris, M. (2018). How outdoor microclimate mitigation affects building thermal-energy performance: A new design-stage method for energy saving in residential near-zero energy settlements in Italy. Renewable Energy, 127: 920-935. https://doi.org/10.1016/j.renene.2018.04.090

[6] Lissén, J.M.S., Rodríguez, L.R., Parejo, F.D., de la Flor, F.J.S. (2018). An economic, energy, and environmental analysis of PV/Micro-CHP hybrid systems: A case study of a tertiary building. Sustainability, 10(11): 1-15. https://doi.org/10.5194/gmd-10-2801-2017

[7] Schoetter, R., Masson, V., Bourgeois, A., Pellegrino, M., Lévy, J.P. (2017). Parametrisation of the variety of human behaviour related to building energy consumption in the Town Energy Balance (SURFEX-TEB v. 8.2). Geoscientific Model Development, 10(7): 2801-2831. https://doi.org/10.5194/gmd-10-2801-2017

[8] Pablo-Romero, M.D.P., Pozo-Barajas, R., Yñiguez, R. (2017). Global changes in residential energy consumption. Energy Policy, 101: 342-352. https://doi.org/10.1016/j.enpol.2016.10.032

[9] Cao, J.F., Li, M.C., Wang, M., Xiong, M.M., Meng, F.C. (2017). Effects of climate change on outdoor meteorological parameters for building energy-saving design in the different climate zones of China. Energy and Buildings, 146: 65-72. https://doi.org/10.1016/j.enbuild.2017.04.045

[10] Zhu, P., Gilbride, M., Yan, D., Sun, H., Meek, C. (2017). Lighting energy consumption in ultra-low energy buildings: Using a simulation and measurement methodology to model occupant behavior and lighting controls. Building Simulation, 10(6): 799-810. https://doi.org/10.1007/s12273-017-0408-6

[11] Fernández, F., Folgueras, M., Suárez, I. (2017). Study and optimization of design parameters in water loop heat pump systems for office buildings in the Iberian Peninsula. $\quad$ Energies, 10(12): 1958. https://doi.org/10.3390/en10121958

[12] Hoffman, M., Rodan, K., Feldman, M., Saposnik, D.S. (1983). Solar heating using common building elements as passive systems. Solar Energy, 30(3): 275-287. https://doi.org/10.1016/0038-092X(83)90157-3

[13] Kabir, E., Kumar, P., Kumar, S., Adelodun, A.A., Kim, K.H. (2018). Solar energy: Potential and future prospects. Renewable and Sustainable Energy Reviews, 82: 894900. https://doi.org/10.1016/j.rser.2017.09.094

[14] Ibrahim, M., Bianco, L., Ibrahim, O., Wurtz, E. (2018). Low-emissivity coating coupled with aerogel-based plaster for walls' internal surface application in buildings: Energy saving potential based on thermal comfort assessment. Journal of Building Engineering, 18: 454466. https://doi.org/10.1016/j.jobe.2018.04.008

[15] Elghamry, R., Hassan, H. (2019). Impact of window parameters on the building envelope on the thermal comfort, energy consumption and cost and environment. International Journal of Ventilation, 1-27. https://doi.org/10.1080/14733315.2019.1665784

[16] Wijesuriya, S., Brandt, M., Tabares-Velasco, P.C. (2018) Parametric analysis of a residential building with phase change material (PCM)-enhanced drywall, precooling, and variable electric rates in a hot and dry climate. Applied Energy, 222: 497-514. https://doi.org/10.1016/j.apenergy.2018.03.119

[17] Ma, H.T., Zhou, W.Y., Lu, X.Y., Ding, Z.Q., Cao, Y. (2016). Application of low cost active and passive energy saving technologies in an ultra-low energy consumption building. Energy Procedia, 88: 807-813. https://doi.org/10.1016/j.egypro.2016.06.132

[18] Garnier, C., Muneer, T., Currie, J. (2018). Numerical and empirical evaluation of a novel building integrated collector storage solar water heater. Renewable Energy, 126: 281-295. https://doi.org/10.1016/j.renene.2018.03.041

[19] Abokersh, M.H., Osman, M., El-Baz, O., El-Morsi, M., Sharaf, O. (2018). Review of the phase change material (PCM) usage for solar domestic water heating systems (SDWHS). International Journal of Energy Research, 42(2): 329-357. https://doi.org/10.1002/er.3765

[20] Shaviv, E. (1981). The influence of the orientation of the main solar glazing on the total energy consumption of a building. Solar Energy, 26: 453-454. https://doi.org/10.1016/0038-092X(81)90225-5

[21] Tolabi, H.B., Moradi, M.H., Ayob, S.B.M. (2014). A review on classification and comparison of different models in solar radiation estimation. International Journal of Energy Research, 38(6): 689-701. https://doi.org/10.1002/er.3161

[22] Owczarek, S., (1997). Vector model for calculation of solar radiation intensity and sums incident on tilted surfaces. Identification for the three sky condition in Warsaw. Renewable Energy, 11(1): 77-96. https://doi.org/10.1016/S0960-1481(96)00117-6

[23] El Mghouchi, Y., Chham, E., Krikiz, M.S., Ajzoul, T., El Bouardi, A. (2016). On the prediction of the daily global solar radiation intensity on south-facing plane surfaces inclined at varying angles. Energy Conversion and Management, 120: 397-411. https://doi.org/10.1016/j.enconman.2016.05.005

[24] Cho, S.H., Kim, W.T., Tae, C.S., Zaheeruddin, M. (2004). Effect of length of measurement period on accuracy of predicted annual heating energy consumption of buildings. Energy Conversion and Management, 45(1819): 2867-2878 https://doi.org/10.1016/j.enconman.2003.12.017

[25] Tian, B.S., Shao, J.X., Xu, M., Liang, B., Yang, S.X. (2013). Practice of low energy solar heating building. Building Energy Efficiency, 41(1): 1-6. https://doi.org/10.3969/j.issn.1673-7237.2013.01.001

[26] Zhou, Z.H., Hu, S., Du, T. (2013). Study on determination of best window-wall ratio of office building in cold area. In Applied Mechanics and Materials, 260: 209-216. https://doi.org/10.4028/www.scientific.net/AMM.260261.209

\section{NOMENCLATURE}

$a \quad$ Room width, $\mathrm{m}$

$h \quad$ Room height, $\mathrm{m}$ 
$H \quad$ Total radiation, $\mathrm{kWh}$

$H_{D \theta} \quad$ Total daily radiation of inclined surface

I Radiation intensity, $\mathrm{W} / \mathrm{m}^{2}$

$I_{0} \quad$ Solar constant: $1,353, \mathrm{~W} / \mathrm{m}^{2}$

HIS Intensity of diffuse sky radiation, $\mathrm{W} / \mathrm{m}^{2}$

$I_{r} \quad$ Intensity of direct solar radiation on the ground, $\mathrm{W} / \mathrm{m}^{2}$

$L \quad$ Room depth, m

$m \quad$ Air mass

$M_{\mathrm{r}} \quad$ Roof heating factor

$M_{\mathrm{w}} \quad$ Wall heating factor

$N_{q} \quad$ Regional wall radiation constant

$N_{r} \quad$ Regional roof radiation constant

$P \quad$ Atmospheric transparency

$q_{H} \quad$ Building heat loss, $\mathrm{W} / \mathrm{m}^{2}$

$q_{H T} \quad$ Heat loss via the envelope structure per unit building area, $\mathrm{W} / \mathrm{m}^{2}$

$q_{I N F}$ Heat loss via air permeation per unit building area, $\mathrm{W} / \mathrm{m}^{2}$

$q_{I H} \quad$ Indoor heat gain per unit building area, W/m $\mathrm{m}^{2}$
$Q \quad$ Heating consumption, $\mathrm{kWh}$

$S \quad$ Area, $\mathrm{m}^{2}$

$T \quad$ Sunshine duration, $\mathrm{h}$

$T_{\text {sta }} \quad$ Time of sunrise, $\mathrm{h}$

$T_{\text {end }} \quad$ Time of sunset, $\mathrm{h}$

$z \quad$ Number of days in the heating season, $\mathrm{d}$

\section{Greek symbols}

$\theta \quad$ Inclination, ${ }^{\circ}$

$\alpha \quad$ Solar azimuth, ${ }^{\circ}$

$\gamma \quad$ Azimuth of inclined surface, ${ }^{\circ}$

$\eta \quad$ Utilization efficiency

\section{Subscripts}

buil Building

roof Roof

win Window

wall Wall 